\title{
CFD Simulation of Heat Transfer and Turbulent Fluid Flow over a Double Forward-Facing Step
}

\author{
Hussein Togun, ${ }^{1,2}$ Ahmed Jassim Shkarah,, ${ }^{2,3}$ S. N. Kazi, ${ }^{1}$ and A. Badarudin ${ }^{1}$ \\ ${ }^{1}$ Department of Mechanical Engineering, University of Malaya, 50603 Kuala Lumpur, Malaysia \\ ${ }^{2}$ Department of Mechanical Engineering, University of Thi-Qar, 64001 Nassiriya, Iraq \\ ${ }^{3}$ Department of Mechanical Engineering, Universiti Teknikal Malaysia Melaka, 75450 Melaka, Malaysia
}

Correspondence should be addressed to Hussein Togun; htokan_2004@yahoo.com

Received 31 August 2013; Revised 10 November 2013; Accepted 10 November 2013

Academic Editor: Oluwole Daniel Makinde

Copyright (C) 2013 Hussein Togun et al. This is an open access article distributed under the Creative Commons Attribution License, which permits unrestricted use, distribution, and reproduction in any medium, provided the original work is properly cited.

\begin{abstract}
Heat transfer and turbulent water flow over a double forward-facing step were investigated numerically. The finite volume method was used to solve the corresponding continuity, momentum, and energy equations using the $K-\varepsilon$ model. Three cases, corresponding to three different step heights, were investigated for Reynolds numbers ranging from 30,000 to 100,000 and temperatures ranging from 313 to $343 \mathrm{~K}$. The bottom of the wall was heated, whereas the top was insulated. The results show that the Nusselt number increased with the Reynolds number and step height. The maximum Nusselt number was observed for case 3, with a Reynolds number of 100,000 and temperature of $343 \mathrm{~K}$, occurring at the second step. The behavior of the Nusselt number was similar for all cases at a given Reynolds number and temperature. A recirculation zone was observed before and after the first and second steps in the contour maps of the velocity field. In addition, the results indicate that the coefficient pressure increased with increasing Reynolds number and step height. ANSYS FLUENT 14 (CFD) software was employed to run the simulations.
\end{abstract}

\section{Introduction}

The goal of this study is to investigate two-dimensional double forward-facing step flows, and the results of numerical computations for different step heights, temperatures, and Reynolds numbers are presented herein. Numerous studies have been performed on single forward- and backwardfacing steps; however, the literature on double forwardand backward-facing steps is very limited, and the physical basis of flow separation and vortex creation remains unclear. Fluid flow over a backward- or forward-facing step generates recirculation zones and subsequent reattachment regions, due to sudden contraction or expansion in flow passages. Many practical engineering applications, such as the cooling of electronic devices, open channels, powergenerating equipment, heat exchangers, combustion chambers, and building aerodynamics, involve separating flows. The first attempts to study heat transfer and fluid flow over forward- or backward-facing steps were made in the 1950's. Later, researchers were able to analyze complex flows in three dimensions due to the development of CFD software. Seban et al. [1] and Seban [2] pioneered the study of fluid flow over backward- and forward-facing steps from a heat transfer perspective. The authors discovered that the maximum heat transfer coefficients occur at the reattachment point and decrease toward the outlet. The effect of stream turbulence on the heat transfer rate in the reattachment region on the bottom surface of a backward-facing step was demonstrated by Mabuchi et al. [3]. Improvements in device capabilities have allowed researchers to measure reattachment points and heat transfer characteristics; Mori et al. [4] used a thermal tuft probe, Kawamura et al. [5, 6] obtained the temporal and spatial parameters of heat transfer in the reattachment region using a new heat flux probe, and Oyakawa et al. $[7,8]$ employed jet discharge. The hydrodynamic characteristics of gas flows past a rib and a downward step in feature separation flow regions were studied by Terekhov et al. [9]. The heat transfer coefficients, temperature distributions, and pressures behind the obstacles as well as the 5-10\% enhancement of heat transfer at the maximum recirculation reported also agree 
with the results reported by Alemasov et al. [10]. Aung [11], Vogel and Eaton [12], Sparrow and Chuck [13], Chen et al. [14], Masatoshi and Kenichiro [15], and Khanafer et al. [16] conducted numerical and experimental studies on the airflow over a horizontal backward-facing step with uniform heat flux or uniform temperature. The authors observed a decrease in the Nusselt number and recirculation zone with increasing buoyancy force and noted that the maximum Nusselt number was observed at the reattachment point. Abu-Mulaweh [17] experimentally studied the turbulent fluid flow and heat transfer of a mixed convection boundary-layer of air flowing over a vertical forward-facing step. The effect of the step height on the local Nusselt number distribution, namely, the increase in the local Nusselt number with increasing step height, reached a maximum value at the reattachment point. Both the inclination angle and step height affected heat transfer and flow behavior for the single forward-facing step studied numerically by Nassab et al. [18].

An early study on turbulent heat transfer and airflow over a double forward-facing step was reported by Yilmaz and Öztop [19]. The top of the wall and steps were insulated, and the bottom of the wall was heated. The authors used $K-\varepsilon$ model and found that the step ratio affected the heat transfer and flow more strongly than the length ratio. Later, Öztop et al. [20] presented a numerical study of heat transfer and turbulent airflow over a double forward-facing step with an obstacle. The bottom of the wall and steps were heated, and the top of the wall was insulated. The results showed that the obstacle aspect ratio (Ar) affected the heat transfer, with the maximum Nusselt number corresponding to $\mathrm{Ar}=1$.

The objective of this paper is to contribute new data regarding water flow over double forward-facing steps to improve the design of heat exchangers.

To the best of the authors' knowledge, turbulent water flow and heat transfer over double forward-facing steps have not been reported in the literature; thus, this work is the first such study.

\section{Numerical Model}

2.1. Physical Model. A schematic diagram of the double forward-facing step and the flow shape employed in this study is presented in Figure 1. The bottoms of the wall and the steps were heated to a given temperature $\left(T_{h}\right)$, while the top of the wall was adiabatic. The first step height $(h 1)$ was varied from 2 to $6 \mathrm{~cm}$ whereas the second step height $(h 2)$ was fixed at $2 \mathrm{~cm}$. The entrance width $(H)$ was $10 \mathrm{~cm}$ while the exit width $(H 2)$ was 6,4 , and $2 \mathrm{~cm}$ according to the first step height. Three cases corresponding to three step heights were investigated, as shown Table 1. In addition, the Reynolds number was varied from 30,000 to 100,000 and calculated based on entrance width $(H)$, and four different temperatures from 313 to $343 \mathrm{~K}$ were adopted.

2.2. Governing Equations. The SIMPLE algorithm couples velocity and pressure $[21,22]$ and links the momentum and mass conservation equations using pressure corrections [23]. Therefore, in this study, the SIMPLE algorithm was combined

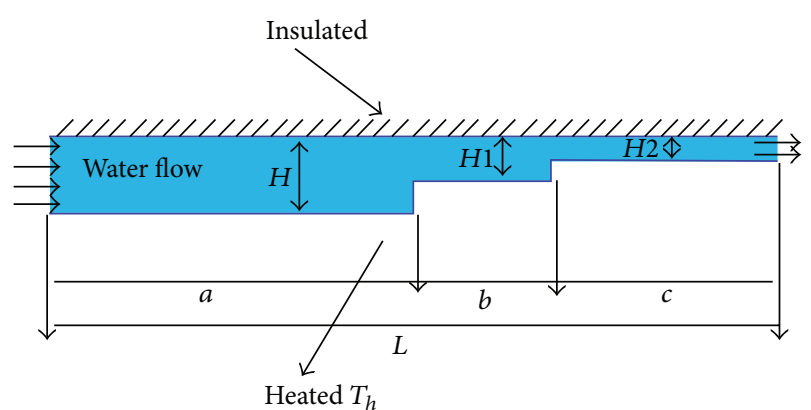

Figure 1: Physical model.

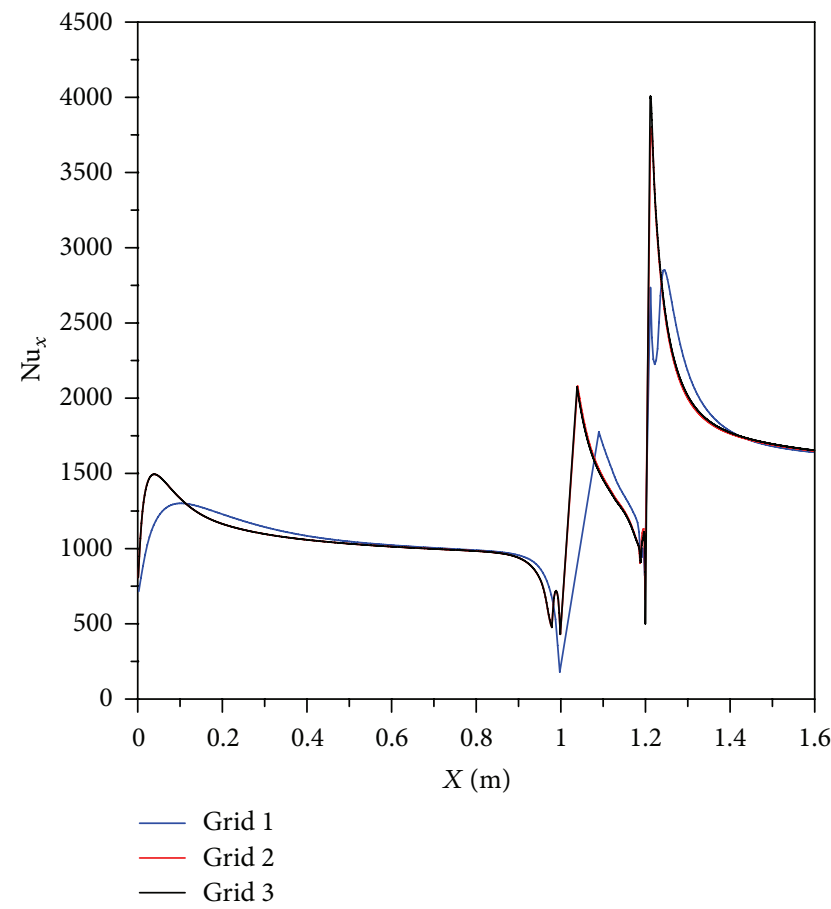

Figure 2: Comparison of Nusselt number case 1, with $\operatorname{Re}=30,000$ and $T=313 \mathrm{~K}$ for grid independent.

with the finite volume method to discretize continuity, $X, Y$ momentum, and energy equations in the computational domain. The conservation equations (1) assuming two dimensions, steady flow and a Newtonian fluid, can be written as follows Yilmaz and Öztop [19]:

$$
\begin{gathered}
\frac{\partial u}{\partial x}+\frac{\partial v}{\partial y}=0, \\
\rho\left(u \frac{\partial u}{\partial x}+v \frac{\partial u}{\partial y}\right)=-\frac{\partial p}{\partial x}+\mu\left(\frac{\partial^{2} u}{\partial x^{2}}+\frac{\partial^{2} u}{\partial y^{2}}\right), \\
\rho\left(u \frac{\partial v}{\partial x}+v \frac{\partial v}{\partial y}\right)=-\frac{\partial p}{\partial y}+\mu\left(\frac{\partial^{2} v}{\partial x^{2}}+\frac{\partial^{2} v}{\partial y^{2}}\right), \\
\rho\left(u \frac{\partial T}{\partial x}+v \frac{\partial T}{\partial y}\right)=\propto\left(\frac{\partial^{2} T}{\partial x^{2}}+\frac{\partial^{2} T}{\partial y^{2}}\right) .
\end{gathered}
$$




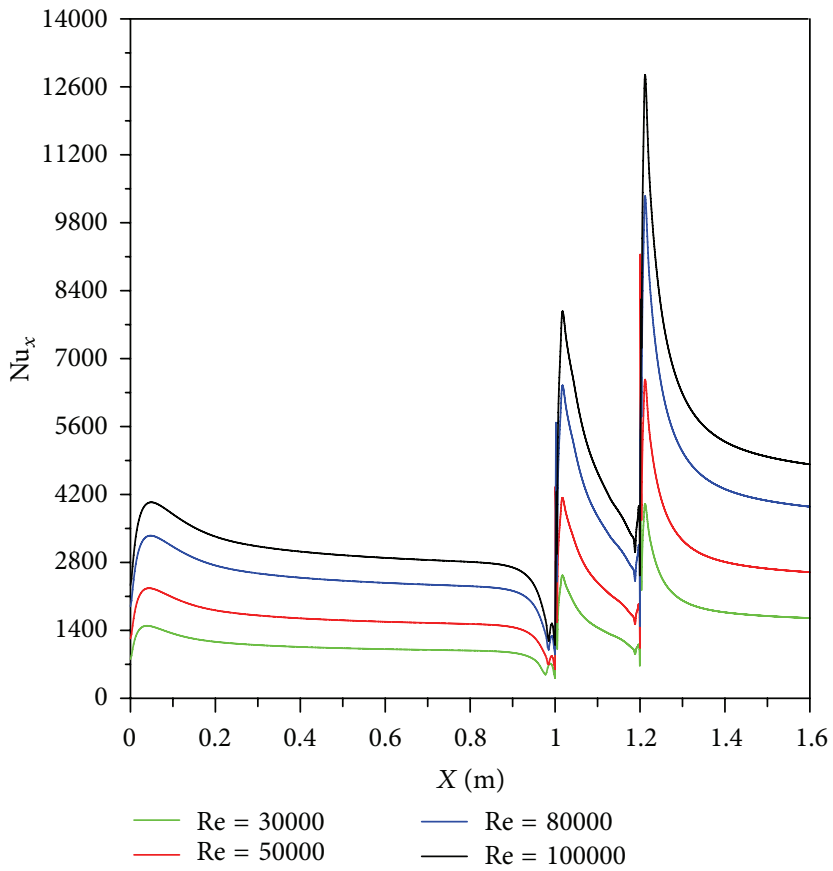

(a)

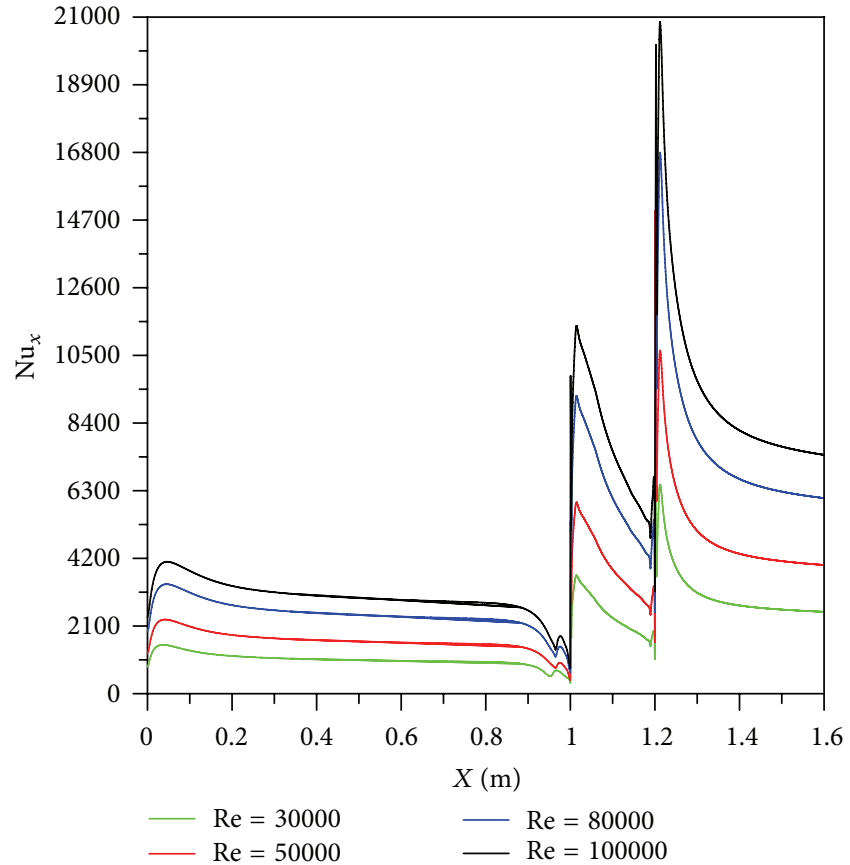

(b)

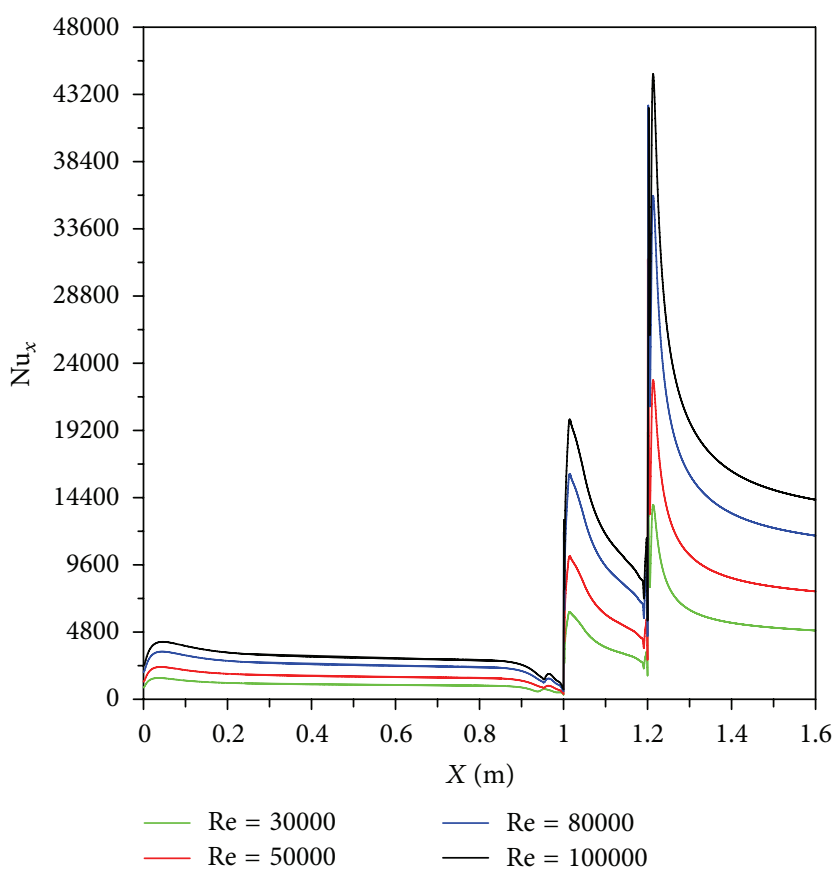

(c)

FIgURE 3: (a) Distribution of local Nusselt number for case 1, with $T=313 \mathrm{~K}$ and different Reynolds number. (b) Distribution of local Nusselt number for case 2, with $T=313 \mathrm{~K}$ and different Reynolds number. (c) Distribution of local Nusselt number for case 3 , with $T=313 \mathrm{~K}$ and different Reynolds number.

TABLE 1: Cases and dimensions of geometries.

\begin{tabular}{lcccccc}
\hline Cases & $H(\mathrm{~cm})$ & $h 1=H-H 1$ & $h 2=H 1-H 2$ & $a(\mathrm{~cm})$ & $b(\mathrm{~cm})$ & $c(\mathrm{~cm})$ \\
\hline 1 & 10 & 2 & 2 & 100 & 20 & 40 \\
2 & 10 & 4 & 2 & 100 & 20 & 40 \\
3 & 10 & 6 & 2 & 100 & 40 \\
\hline
\end{tabular}




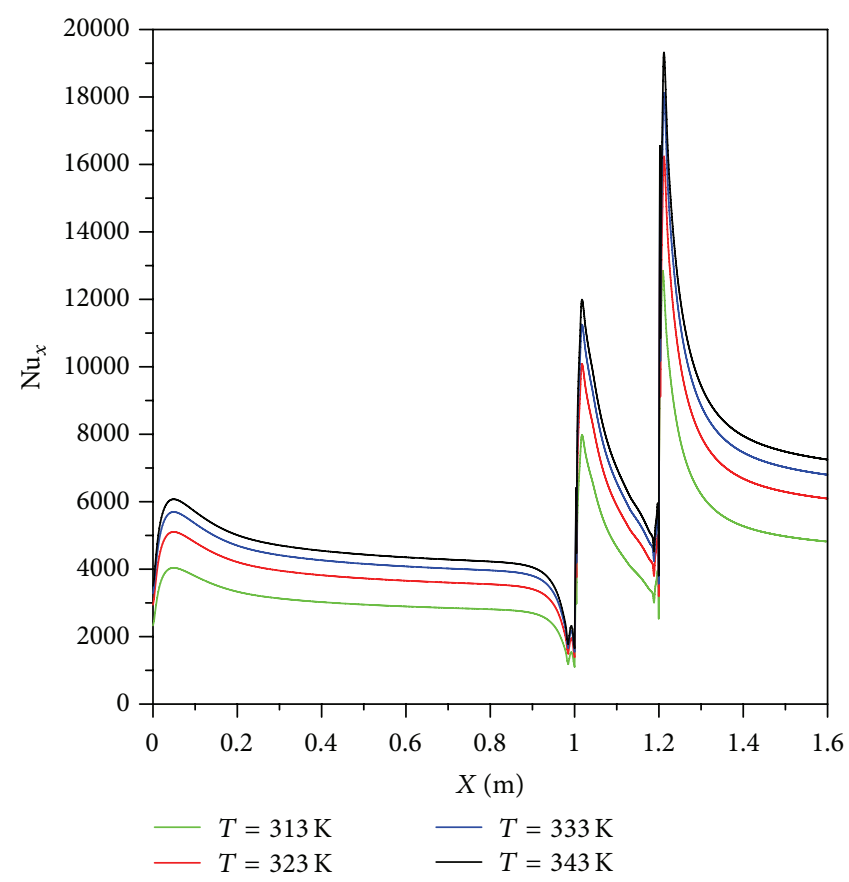

(a)

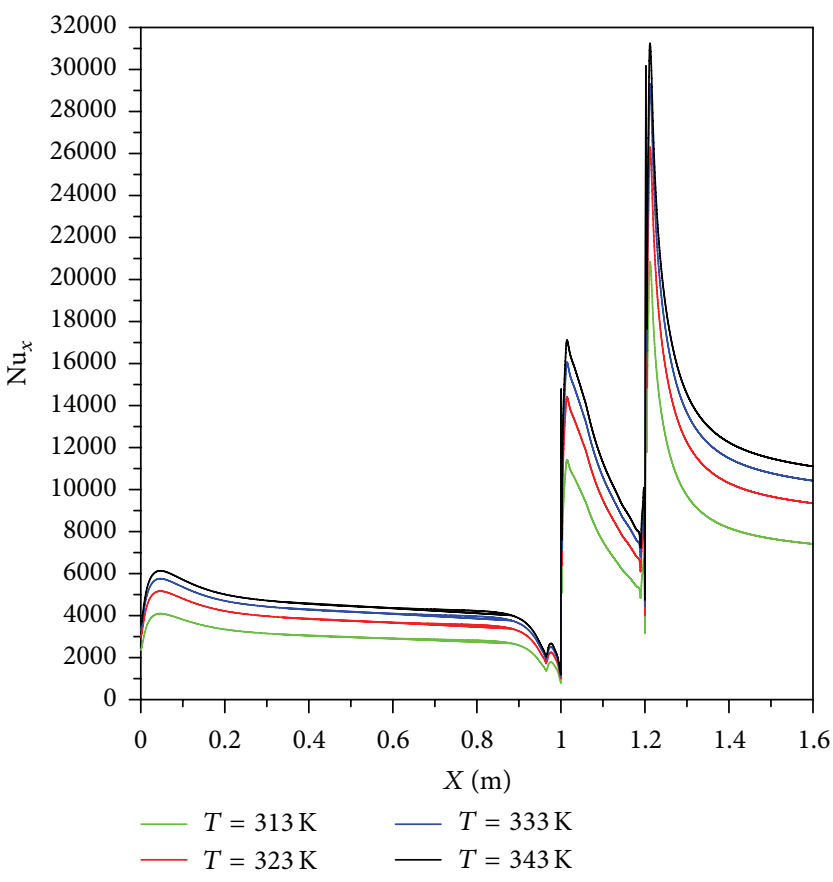

(b)

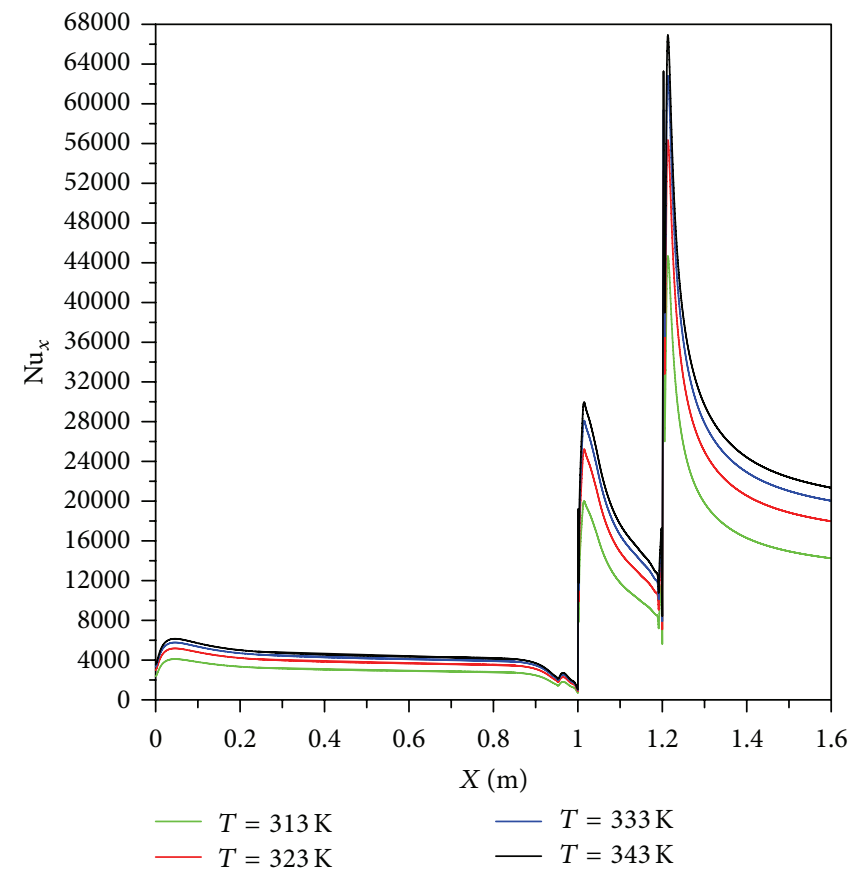

(c)

Figure 4: (a) Local Nusselt number distribution for case 1, with $\mathrm{Re}=100,000$ and different temperatures. (b) Local Nusselt number distribution for case $2 \mathrm{Re}=100,000$ and different temperatures. (c) Local Nusselt number distribution for case 3, with $\mathrm{Re}=100,000$ and different temperatures. 


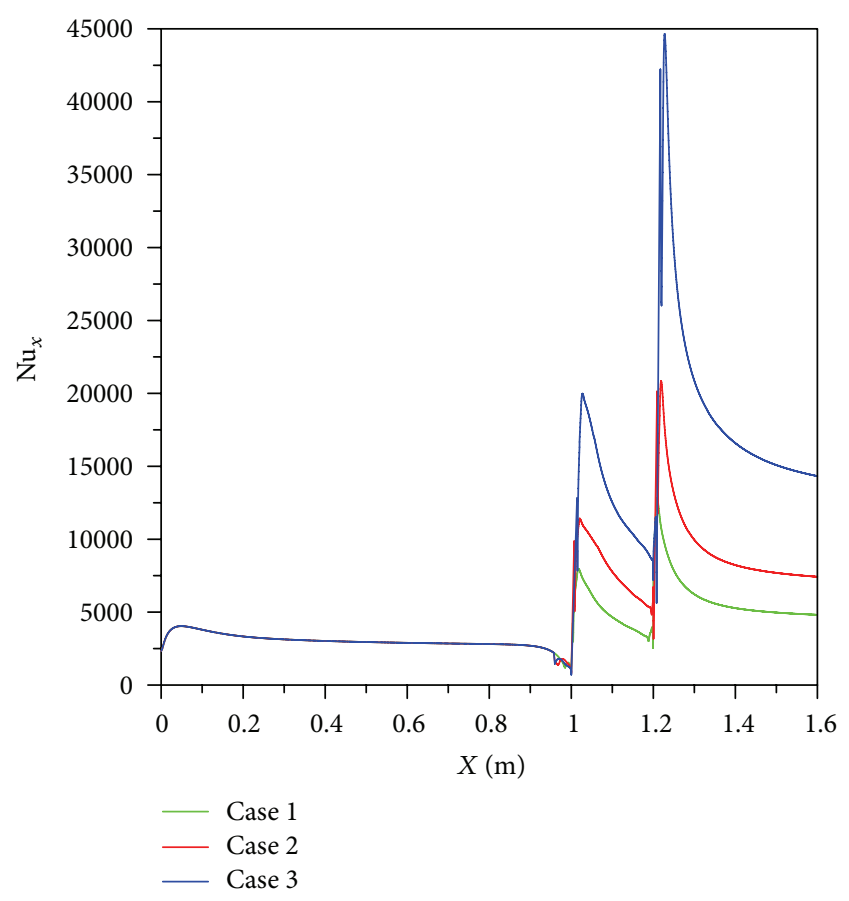

FIGURE 5: Effect step height on local Nusselt number for cases 1, 2, and 3 at $\operatorname{Re}=100,000$ and $T=313 \mathrm{~K}$.

TABLE 2: Value of the constants in transport equations.

\begin{tabular}{lcc}
\hline \multicolumn{3}{c}{ Value of constants } \\
\hline$C_{1 \varepsilon}$ & 1.44 \\
$C_{2 \varepsilon}$ & 1.92 \\
$C_{3 \varepsilon}$ & 0.09 \\
$\sigma_{k}$ & 1.0 \\
$\sigma_{\varepsilon}$ & 1.3 \\
$\operatorname{Pr}$ & 7.01 \\
\hline
\end{tabular}

TABLE 3: Computational conditions.

\begin{tabular}{lc}
\hline Computational conditions & \\
\hline Fluid & Water \\
Pressure-velocity coupling & Simple \\
(Scheme) & $998.2 \mathrm{~g} / \mathrm{m}^{3}$ \\
Density & $0.001 \mathrm{~kg} / \mathrm{m} \cdot \mathrm{s}$ \\
Viscosity & $101,325 \mathrm{~Pa}$ \\
Pressure & $k$ and $\varepsilon$ \\
Viscous model & \\
Reynolds number & $30,000,50,000,80,000,100,000$ \\
$($ Re $=\rho U H / \mu)$ & $313,323,333,343 \mathrm{~K}$ \\
Temperature &
\end{tabular}

The standard $k-\varepsilon$ turbulence model was employed for turbulence flow modeling [24]. In FLUENT, near-wall treatment based on standard wall functions was selected for high accuracy results where it was suggested by Chung and Jia [25] for predication separation flow and heat transfer in sudden expansion. The transport equations were applied to determine the turbulence kinetic energy $k(2)$ and dissipation rate $\varepsilon(3)$ :

$$
\begin{aligned}
\frac{\partial}{\partial x}(\rho k u)= & \frac{\partial}{\partial y}\left(\left[\left(\mu+\frac{\mu_{t}}{\sigma_{k}}\right) \frac{\partial k}{\partial y}\right]\right)+G_{k}-\rho \varepsilon, \\
\frac{\partial}{\partial x}(\rho \varepsilon u)= & \frac{\partial}{\partial y}\left(\left[\left(\mu+\frac{\mu_{t}}{\sigma_{\varepsilon}}\right) \frac{\partial \varepsilon}{\partial y}\right]\right) \\
& +C_{1 \varepsilon} \frac{\varepsilon}{k}\left(G_{k}+C_{3 \varepsilon} G_{b}\right)-C_{2 \varepsilon} \rho \frac{\varepsilon^{2}}{k},
\end{aligned}
$$

where $G_{k}$ describes the generation of turbulence kinetic energy by the turbulent viscosity and velocity gradients and is computed using

$$
G_{k}=-\rho \overline{v^{\prime} u} \frac{\partial v}{\partial x}
$$

$\mu_{t}$ is calculated using

$$
\mu_{t}=\rho C_{p} \frac{k^{2}}{\varepsilon} .
$$

The values of the constants employed in the simulations are shown in Table 2.

To enhance the accuracy of the simulations, the secondorder upwind scheme was used. Additionally, after each iteration, the residual sum was computed and stored for every conserved variable. The required scaled residual for the convergence criterion was less than $10^{-8}$ for the continuity and smaller than $10^{-7}$ for the energy and momentum equations.

\section{Numerical Procedure and Code Validation}

Simulations were carried out using ANSYS FLUENT 14 (CFD). The ICEM was used for meshing, and the $k-\varepsilon$ standard model in Fluent was used to analyze the water flow and heat transfer over the double forward-facing step in the turbulent region. The computational conditions used in the numerical simulation are shown in Table 3. Grid independence was verified by increasing the grid size step wise, which yielded similar results. Independent verification was performed for $\operatorname{Re}=30,000$, case 1 , and initial grid sizes of 9099, 37397, and 67117. The difference in the Nusselt number relative to that of the selected grid was less than $1 \%$ as shown Figure 2. The geometric dimensions were based on those reported by [19]

\section{Results and Discussion}

Numerical simulations were performed for heat transfer and turbulent water flow over a double forward-facing step. Three cases with different step heights at Reynolds numbers of $30,000,50,000,80,000$, and 100,000 and temperatures of 313 , 323,333 , and $343 \mathrm{~K}$ were studied.

4.1. Nusselt Number. Figures 3(a), 3(b), and 3(c) show the variation in the local Nusselt number for cases 1, 2, and 3 at $T=343 \mathrm{~K}$ and different Reynolds numbers. In all cases, the Nusselt number increased with the Reynolds number, 

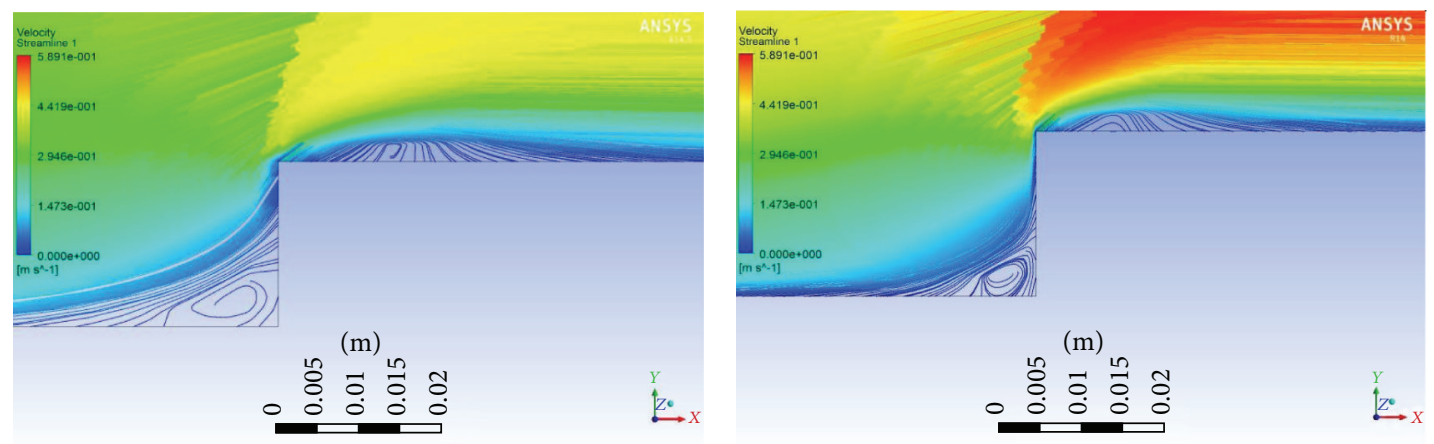

(a)
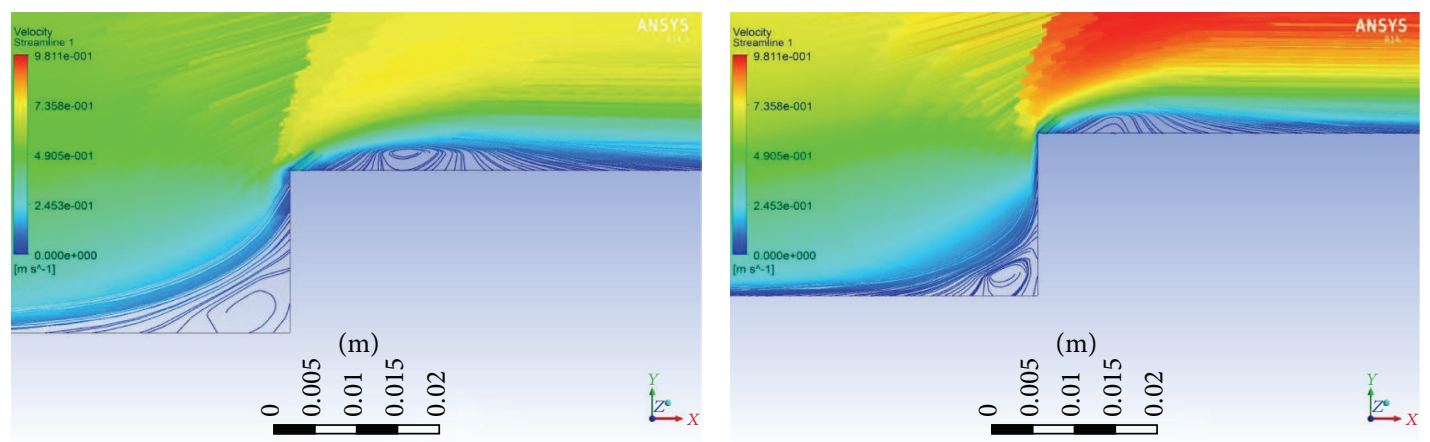

(b)
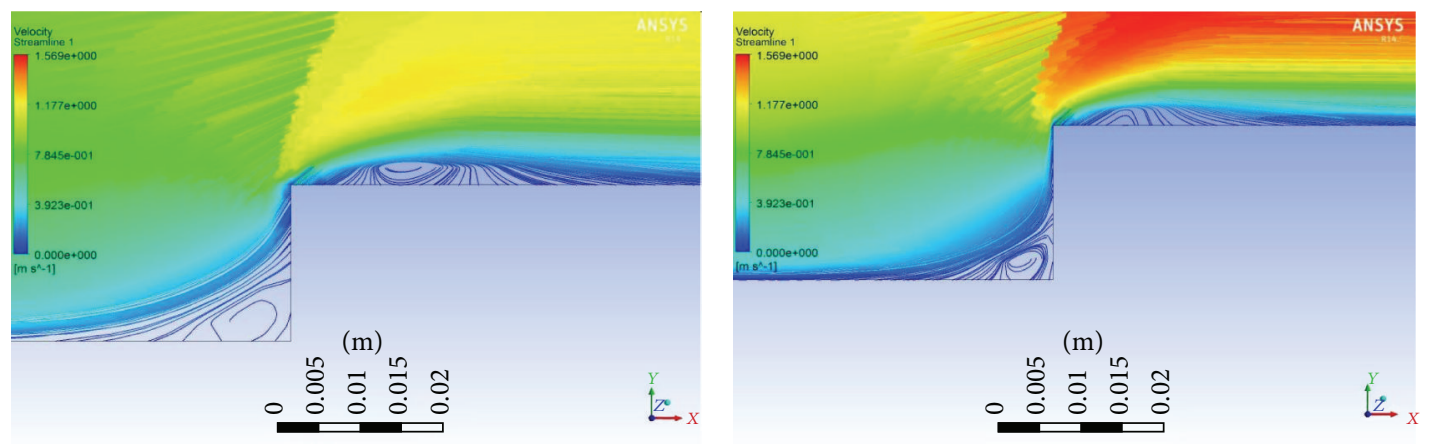

(c)
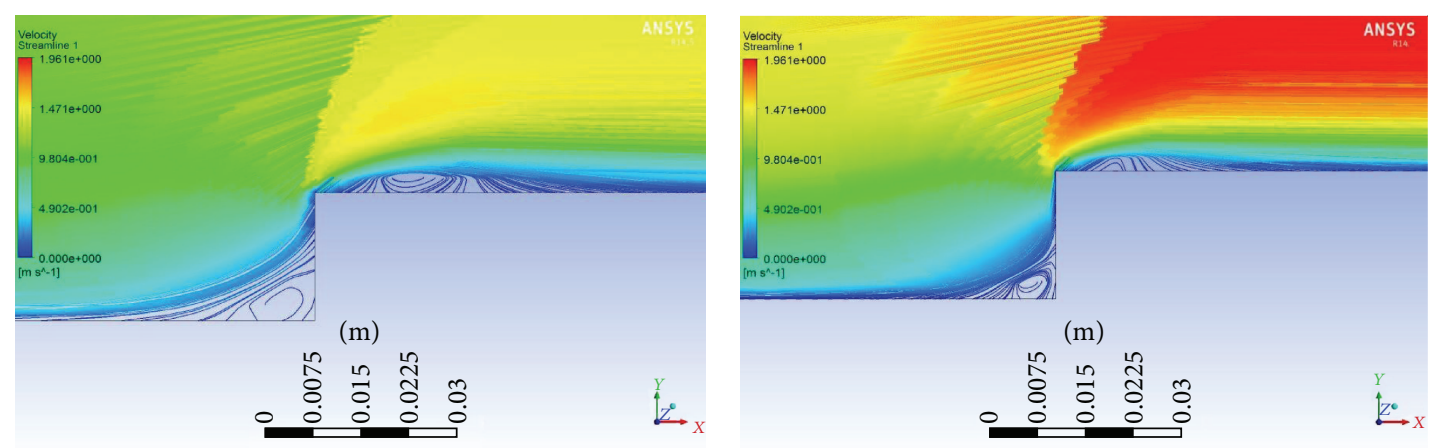

(d)

Figure 6: (a) Velocity of streamline for case 1, with $\mathrm{Re}=30,000$ and $T=313 \mathrm{~K}$. (1) First step. (2) Second step. (b) Velocity of streamline for case 1, with $\mathrm{Re}=50,000$ and $T=313 \mathrm{~K}$. (1) First step. (2) Second step. (c) Velocity of streamline for case 1, with $\mathrm{Re}=80,000$ and $T=313 \mathrm{~K}$. (1) First step. (2) Second step. (d) Velocity of streamline for case 1, with $\operatorname{Re}=100,000$ and $T=313$ K. (1) First step. (2) Second step. 


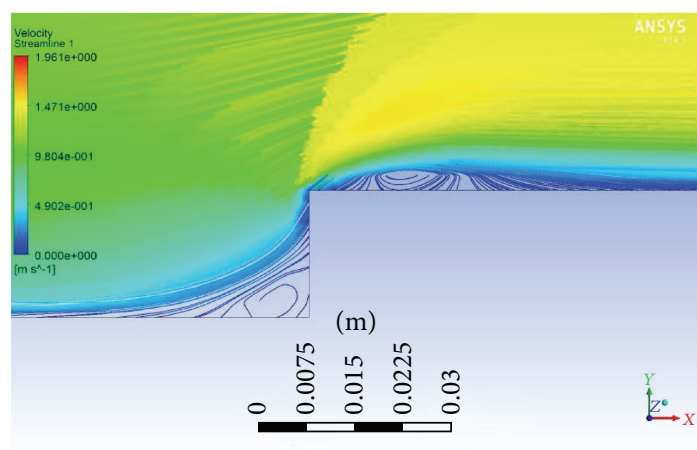

(a)

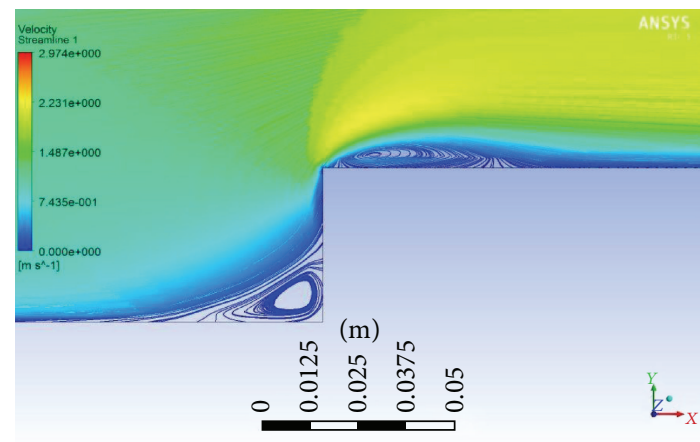

(b)

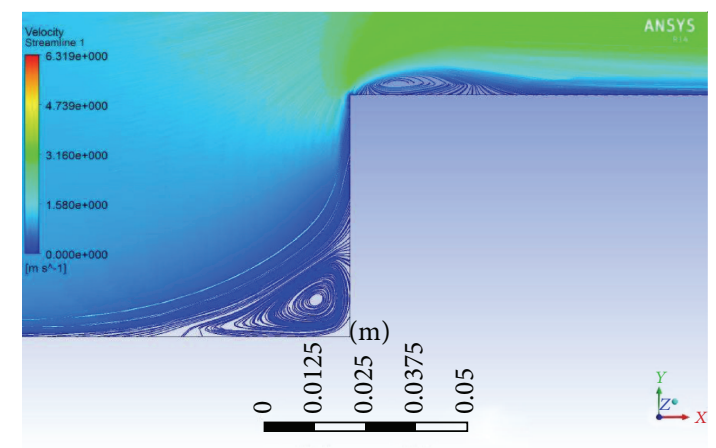

(c)

Figure 7: Effect step height on recirculation region for $\mathrm{Re}=100,000$ and $T=313 \mathrm{~K}$. (a) Case 1 at first step. (b) Case 2 at first step. (c) Case 3 at first step.

and a sudden increase in the Nusselt number was observed at the first and second steps due to recirculation vortices. A higher Nusselt number occurred at the second step for case 3 compared to the Nusselt numbers observed in other cases. The effect of temperature on the local Nusselt number for cases 1, 2, and 3 is illustrated in Figures 4(a), 4(b), and 4(c). As shown, the trends of the Nusselt number are similar before the first and second steps, and the Nusselt number decreases sharply at the same Reynolds number for all cases. A decrease in temperature leads to a decrease in the Nusselt number. For all temperatures, the maximum value of the Nusselt number was observed at the first and second steps for all cases; in case 3 , however, a higher Nusselt number occurred at the second step compared with the numbers observed in the other cases, as shown in Figure 5.

4.2. Flow Visualization. Figures 6(a), 6(b), 6(c), and 6(d) present the contour maps of the velocity field for case 1 at $T=313 \mathrm{~K}$ and various Reynolds numbers. Generally, the recirculation zone is found before and after the first and second step, with the recirculation zone around the first step being larger than that around the second step for a given Reynolds number and temperature. The recirculation zone also increased with Reynolds number for case 1 at $T=313 \mathrm{~K}$. The effect of the step height on the recirculation zone is illustrated in Figures 7(a), 7(b), 7(c), 8(a), 8(b), and 8(c) for cases 1,2 , and $3, \operatorname{Re}=100,000$, and $T=313 \mathrm{~K}$. Increasing the step height increased the recirculation flow, and the largest recirculation zone was found at the first step for case 3, $\operatorname{Re}=100,000$, and $T=313 \mathrm{~K}$ relative to that observed in case 1 and 2 .

4.3. Pressure Coefficient. Figure 9(a) shows the pressure coefficient along the $x$-axis for case 1 at $T=313 \mathrm{~K}$ and different Reynolds numbers. Increasing the Reynolds number led to an increase in the pressure coefficients, particularly at the first and second step, which in turn increased the recirculation flow and enhanced the heat transfer rate. Figure 9(b) presents the pressure coefficients at $T=313 \mathrm{~K}$ and $\mathrm{Re}=100,000$ for cases 1, 2, and 3. Case 3 shows the highest pressure coefficient and thus the largest increase in the Nusselt number.

Figure 10 compares the Nusselt number for case 1, with $\mathrm{Re}=30,000$ and $T=313 \mathrm{~K}$, with the values reported by [18, 20]. An acceptable agreement between the trends, especially at the step region, justifies the use of this computational approach. For more validation, compare the local Nusselt number for case 2, at Reynolds number of 30000 and $T=313 \mathrm{~K}$, with case 10 of [19] presented in Figure 11.

\section{Conclusion}

Turbulent forced convection and heat transfer over a double forward-facing step was studied. Three cases, corresponding to three different step heights, were investigated at 


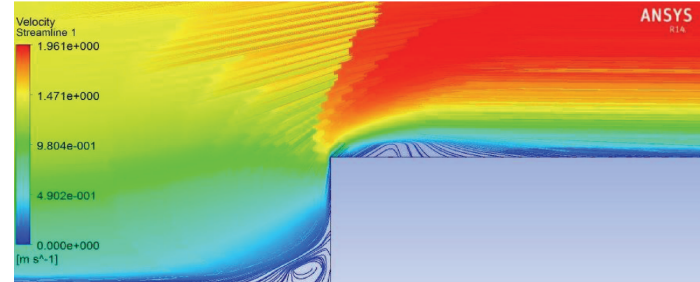

$(\mathrm{m})$

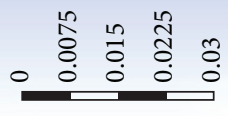

(a)

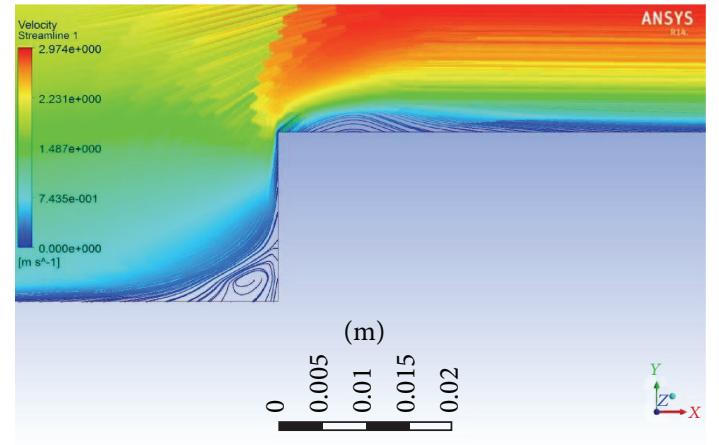

(b)

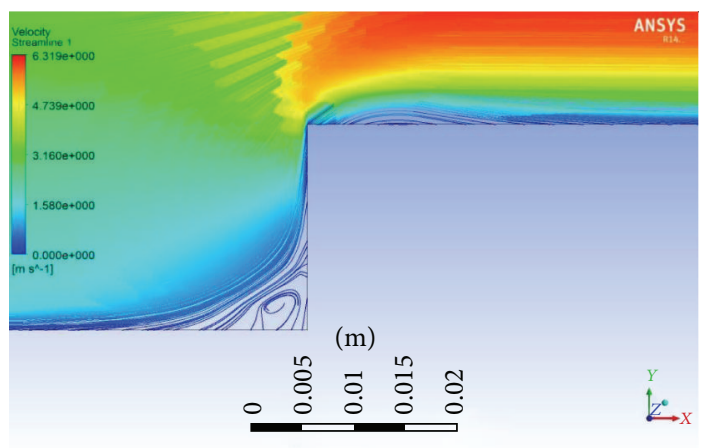

(c)

Figure 8: Effect step height on recirculation region for $\mathrm{Re}=100,000$ and $T=313 \mathrm{~K}$. (a) Case 1 at second step. (b) Case 2 at second step. (c) Case 3 at second step.

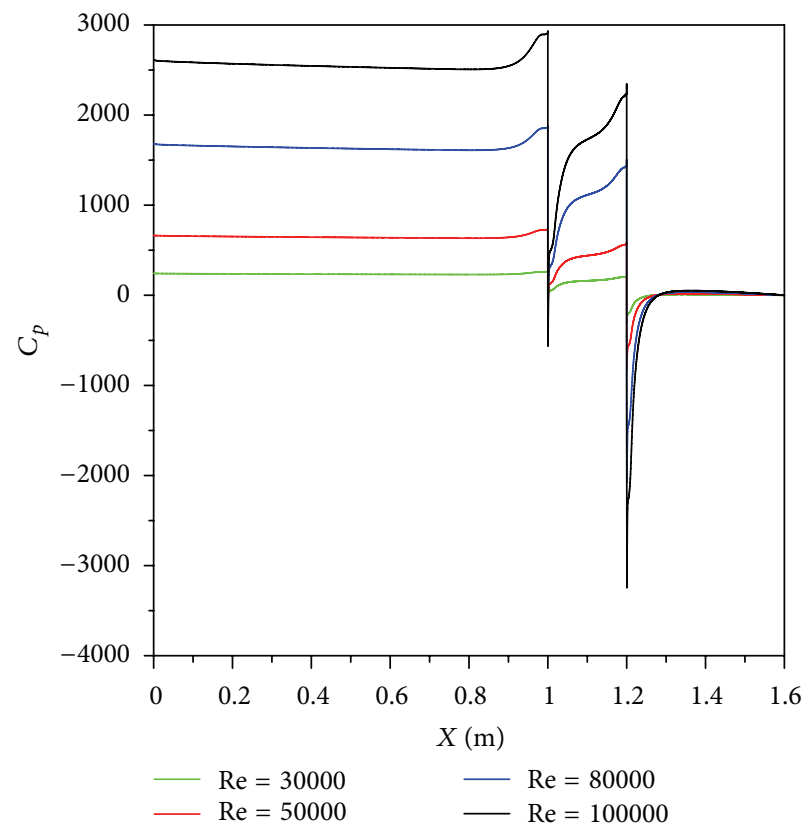

(a)

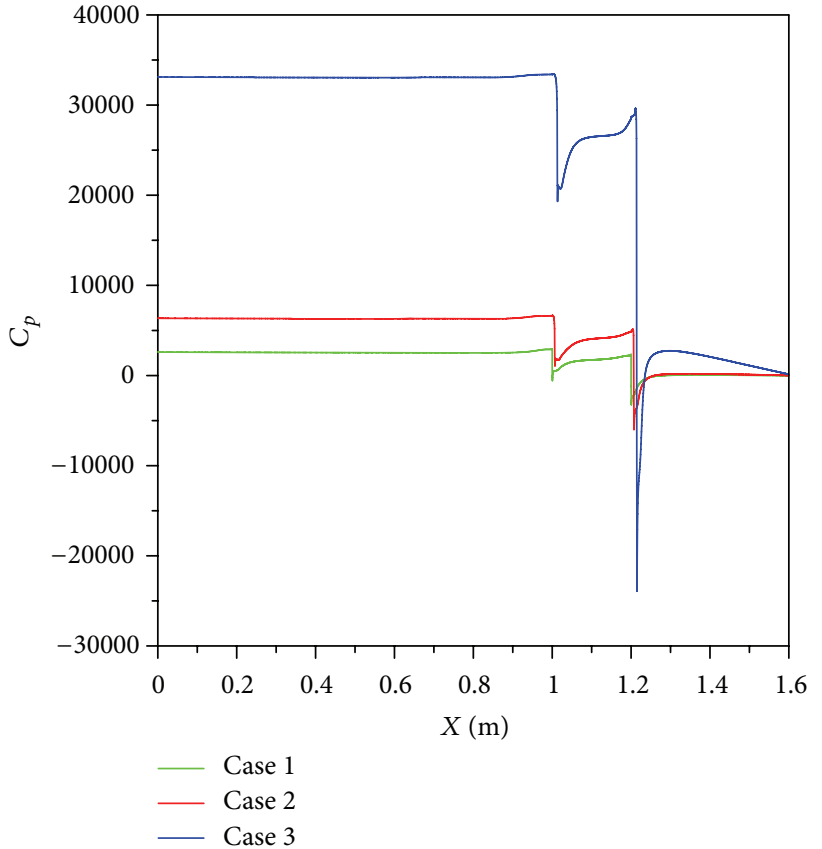

(b)

FIGURE 9: (a) Variation of pressure coefficient for case 1, with $T=313 \mathrm{~K}$ and different Reynolds number. (b) Effect step height on pressure coefficient at $\operatorname{Re}=100,000$ and $T=313 \mathrm{~K}$. 


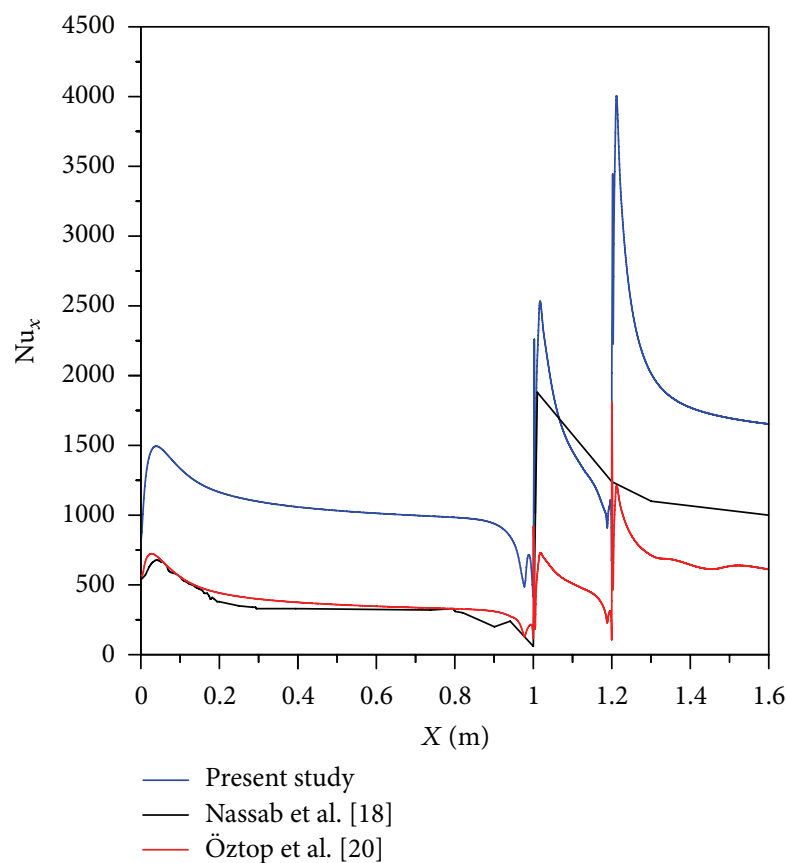

FIGURE 10: Comparison of trend of Nusselt number with $[18,20]$ for case $1 \operatorname{Re}=30,000$ and $T=313 \mathrm{~K}$.

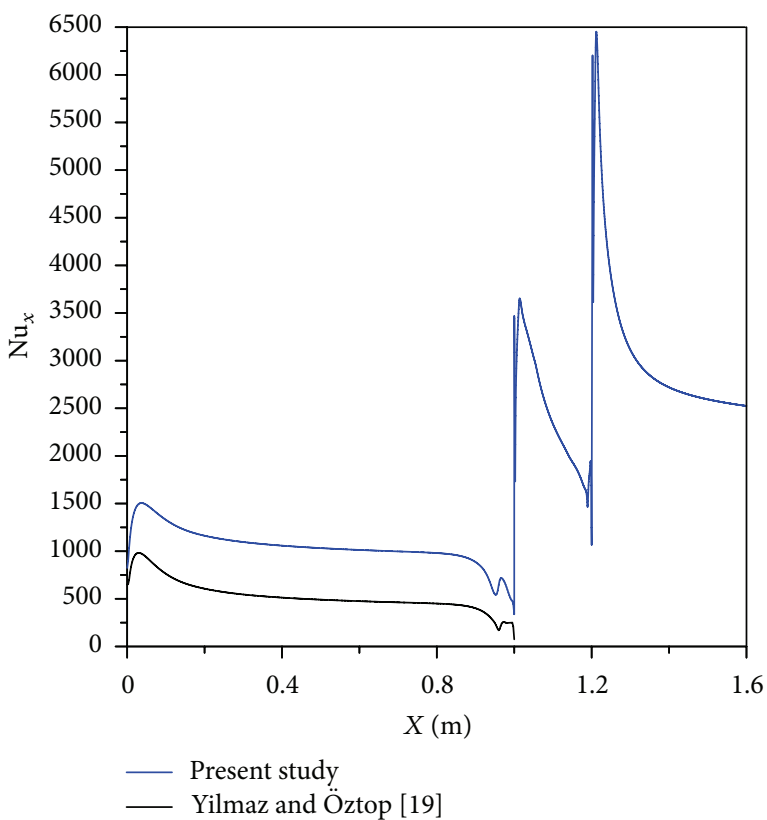

FIgURE 11: Comparison of trend of Nusselt number for case 2 $\operatorname{Re}=30,000$ and $T=313 \mathrm{~K}$ with case 10 of [19].

four Reynolds numbers and four temperatures. The results show that increasing the Reynolds number and temperature increased the Nusselt number for all cases. The enhancement of the Nusselt number occurred at the first and second steps due to separation flow, and the highest augmentation was observed at the second step for case 3 relative to the values observed in cases 1 and 2. The effect of step height on the recirculation zone increased the separation length at the same Reynolds number and temperature, which increases the Nusselt number. In addition, the obtained results indicate an increase in the pressure coefficient with increasing Reynolds number and step height.

\section{Nomenclature}

$\begin{array}{ll}a: & \begin{array}{l}\text { Length of bottom wall before the } \\ \text { first step }\end{array} \\ b: & \begin{array}{l}\text { Length of bottom wall after the } \\ \text { first step }\end{array} \\ c: & \begin{array}{l}\text { Length of bottom wall after the } \\ \text { second step }\end{array} \\ C_{1 \varepsilon}, C_{2 \varepsilon}, C_{3 \varepsilon}, \sigma_{k}, \sigma_{\varepsilon}: & \text { Model constants } \\ C_{p}: & \text { Specific heat } \\ H: & \text { Width of channel before the steps } \\ H 1: & \text { Width of channel after first step } \\ H 2: & \text { Width of channel after second step } \\ h 1: & \text { Height of first step } \\ h 2: & \text { Height of second step } \\ L: & \text { Total length of channel } \\ K: & \text { Turbulent energy } \\ \text { Nu: } & \text { Nusselt number } \\ P: & \text { Pressure } \\ \operatorname{Pr}: & \text { Prandtl number } \\ \operatorname{Re}: & \text { Reynolds number } \\ T: & \text { Temperature } \\ U: & \text { Mean velocity } \\ u, v: & \text { Axial velocity } \\ X, y: & \text { Cartesian coordinates }\end{array}$

\section{Greek Symbols}

$\rho$ : Water density

$\varepsilon$ : Turbulent dissipation

$\mu$ : Dynamic viscosity

$\mu_{t}$ : Turbulent viscosity.

\section{Acknowledgments}

The authors gratefully acknowledge Grant UMRG RP012D13AET, Tuqa Abdularazzaq (UPM), and the University of Malaya, Malaysia, for support in conducting this research.

\section{References}

[1] R. A. Seban, A. Emery, and A. Levy, "Heat transfer to separated and reattached subsonic turbulent flows obtained downstream of a surface step," International Journal of Aerospace Sciences, vol. 2, pp. 809-814, 1959.

[2] R. A. Seban, "The effect of suction and injection on the heat transfer and flow in a turbulent separated air flow," Journal of Heat Transfer, vol. 88, no. 3, pp. 276-282, 1966.

[3] I. Mabuchi, T. Murata, and M. Kumada, "Effect of free-stream turbulence on heat transfer characteristics in the reattachment region on the bottom surface of a backward-facing step (for 
different angles of separation)," Transactions of the Japan Society of Mechanical Engineers B, vol. 52, no. 479, pp. 2619-2625, 1986.

[4] Y. Mori, Y. Uchida, and K. Sakai, "A study of the time and spatial micro-structure of heat transfer performance near the reattaching point of separated flows," Transactions of the Japan Society of Mechanical Engineers B, vol. 52, no. 481, pp. 3353-3361, 1986.

[5] T. Kawamura, A. Yamamori, J. Mimatsu, and M. Kumada, "Time and spatial characteristics of heat transfer at the reattachment region of a two-dimensional backward-facing step," in Proceedings of the ASME-JSME Thermal Engineering Joint Conference, vol. 3, pp. 197-204, 1991.

[6] T. Kawamura, S. Tanaka, I. Mabuchi, and M. Kumada, “Temporal and spatial characteristics of heat transfer at the reattachment region of a backward-facing step," Experimental Heat Transfer, vol. 1, no. 4, pp. 299-313, 1987.

[7] K. Oyakawa, T. Taira, and E. Yamazato, "Studies of heat transfer control by jet discharge at reattachment region downstream of a backward-facing step," Transactions of the Japan Society of Mechanical Engineers B, vol. 60, no. 569, pp. 248-254, 1994.

[8] K. Oyakawa, T. Saitoh, I. Teruya, and I. Mabuchi, "Heat transfer enhancement using slat at reattachment region downstream of backward-facing step," Transactions of the Japan Society of Mechanical Engineers B, vol. 61, no. 592, pp. 4426-4431, 1995.

[9] V. I. Terekhov, N. I. Yarygina, and R. F. Zhdanov, "Heat transfer in turbulent separated flows in the presence of high free-stream turbulence," International Journal of Heat and Mass Transfer, vol. 46, no. 23, pp. 4535-4551, 2003.

[10] V. E. Alemasov, G. A. Glebov, and A. P. Kozlov, ThermoAnemometric Methods for Studying Flows with Separation, vol. 178, Kazan'Branch of the USSR Academy of Sciences, Kazan, Russia, 1989.

[11] W. Aung, "An experimental study of laminar heat transfer downstream of backstep," Journal of Heat Transfer, vol. 105, no. 4, pp. 823-829, 1983.

[12] J. C. Vogel and J. K. Eaton, "Combined heat transfer and fluid dynamic measurements downstream of a backward-facing step," Journal of Heat Transfer, vol. 107, no. 4, pp. 922-929, 1985.

[13] E. M. Sparrow and W. Chuck, "PC solutions for the heat transfer and fluid flow downstream of an abrupt asymmetric enlargement in a channel," Numerical Heat Transfer, vol. 12, no. 1, pp. 19-40, 1987.

[14] Y. T. Chen, J. H. Nie, B. F. Armaly, and H. T. Hsieh, "Turbulent separated convection flow adjacent to backward-facing stepeffects of step height," International Journal of Heat and Mass Transfer, vol. 49, no. 19-20, pp. 3670-3680, 2006.

[15] S. I. S. Masatoshi and S. Kenichiro, "Control of turbulent channel flow over a backward-facing step by suction," Journal of Fluid Science and Technology, vol. 4, no. 1, pp. 188-199, 2009.

[16] K. Khanafer, B. Al-Azmi, A. Al-Shammari, and I. Pop, "Mixed convection analysis of laminar pulsating flow and heat transfer over a backward-facing step," International Journal of Heat and Mass Transfer, vol. 51, no. 25-26, pp. 5785-5793, 2008.

[17] H. I. Abu-Mulaweh, "Turbulent mixed convection flow over a forward-facing step-the effect of step heights," International Journal of Thermal Sciences, vol. 44, no. 2, pp. 155-162, 2005.

[18] S. A. G. Nassab, R. Moosavi, and S. M. H. Sarvari, “Turbulent forced convection flow adjacent to inclined forward step in a duct," International Journal of Thermal Sciences, vol. 48, no. 7, pp. 1319-1326, 2009.
[19] I. Yilmaz and H. F. Öztop, "Turbulence forced convection heat transfer over double forward facing step flow," International Communications in Heat and Mass Transfer, vol. 33, no. 4, pp. 508-517, 2006.

[20] H. F. Öztop, K. S. Mushatet, and İ. Yılmaz, "Analysis of turbulent flow and heat transfer over a double forward facing step with obstacles," International Communications in Heat and Mass Transfer, vol. 39, no. 9, pp. 1395-1403, 2012.

[21] A. H. Mahmoudi, M. Shahi, and F. Talebi, "Entropy generation due to natural convection in a partially open cavity with a thin heat source subjected to a nanofluid," Numerical Heat Transfer A, vol. 61, no. 4, pp. 283-305, 2012.

[22] M. Rahgoshay, A. A. Ranjbar, and A. Ramiar, "Laminar pulsating flow of nanofluids in a circular tube with isothermal wall," International Communications in Heat and Mass Transfer, vol. 39, no. 3, pp. 463-469, 2012.

[23] S. V. Patankar and D. B. Spalding, "A calculation procedure for heat, mass and momentum transfer in three-dimensional parabolic flows," International Journal of Heat and Mass Transfer, vol. 15, no. 10, pp. 1787-1806, 1972.

[24] B. E. Launder and D. B. Spalding, "The numerical computation of turbulent flows," Computer Methods in Applied Mechanics and Engineering, vol. 3, no. 2, pp. 269-289, 1974.

[25] B. T. F. Chung and S. Jia, "A turbulent near-wall model on convective heat transfer from an abrupt expansion tube," Heat and Mass Transfer, vol. 31, no. 1-2, pp. 33-40, 1995. 


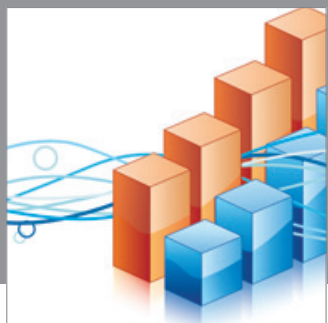

Advances in

Operations Research

mansans

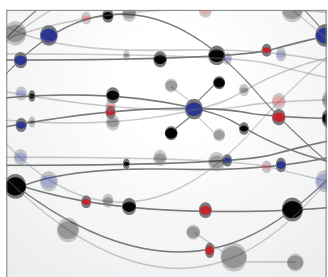

The Scientific World Journal
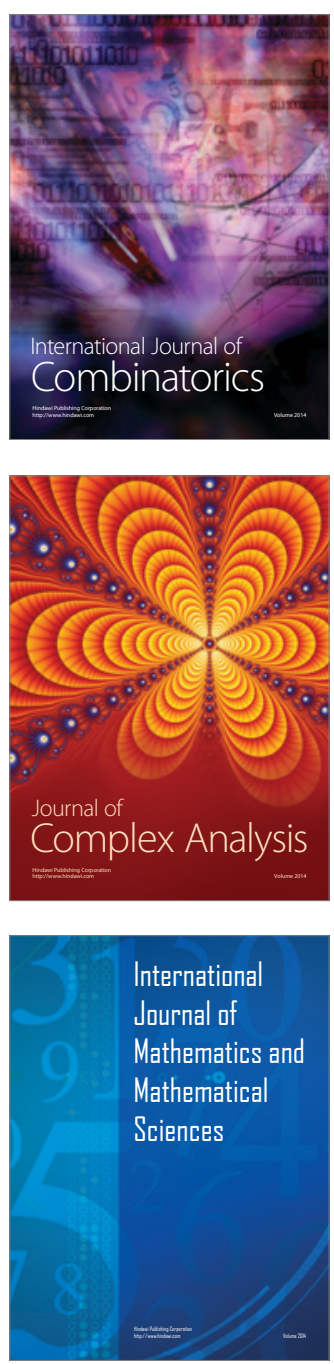
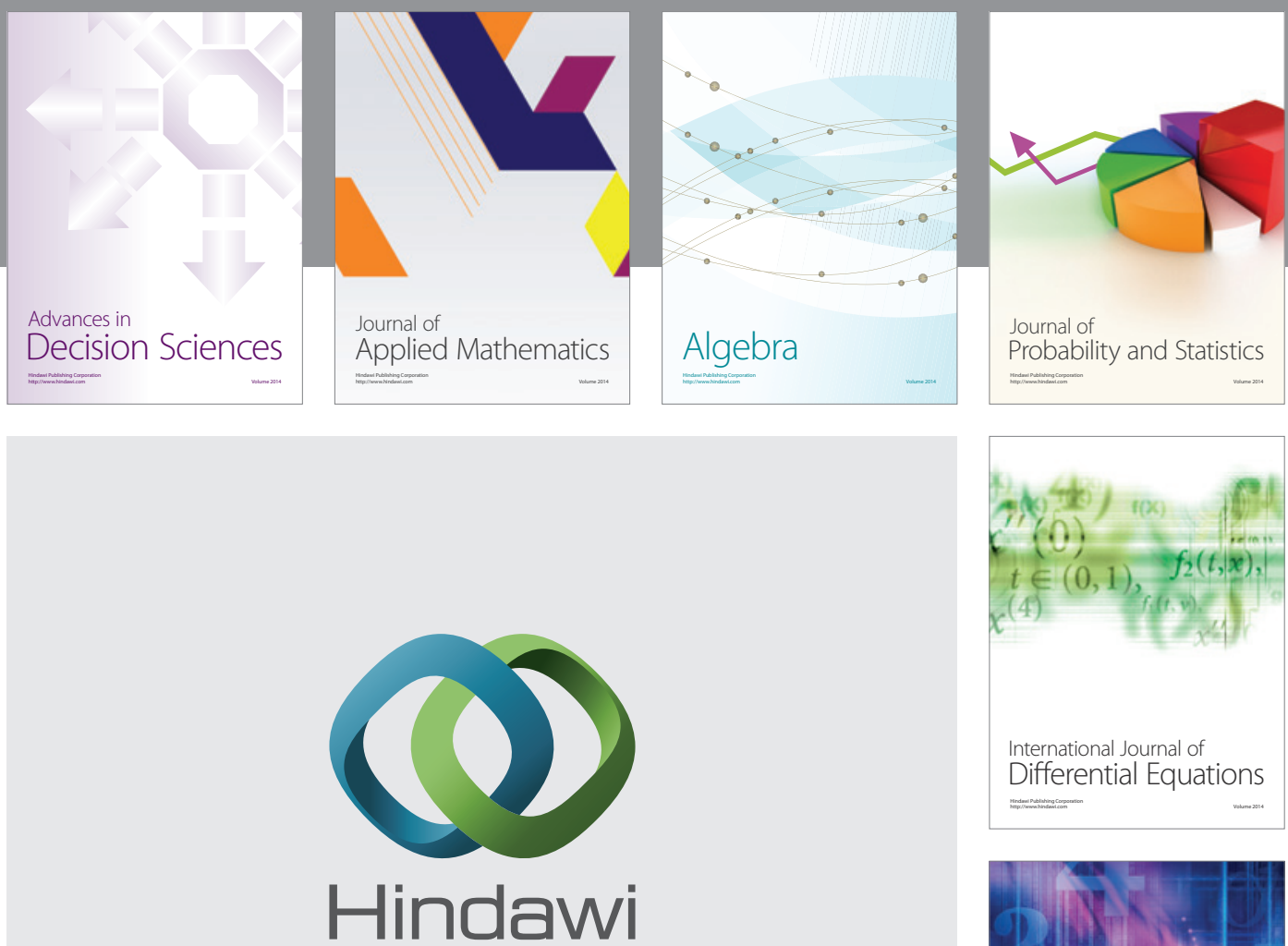

Submit your manuscripts at http://www.hindawi.com
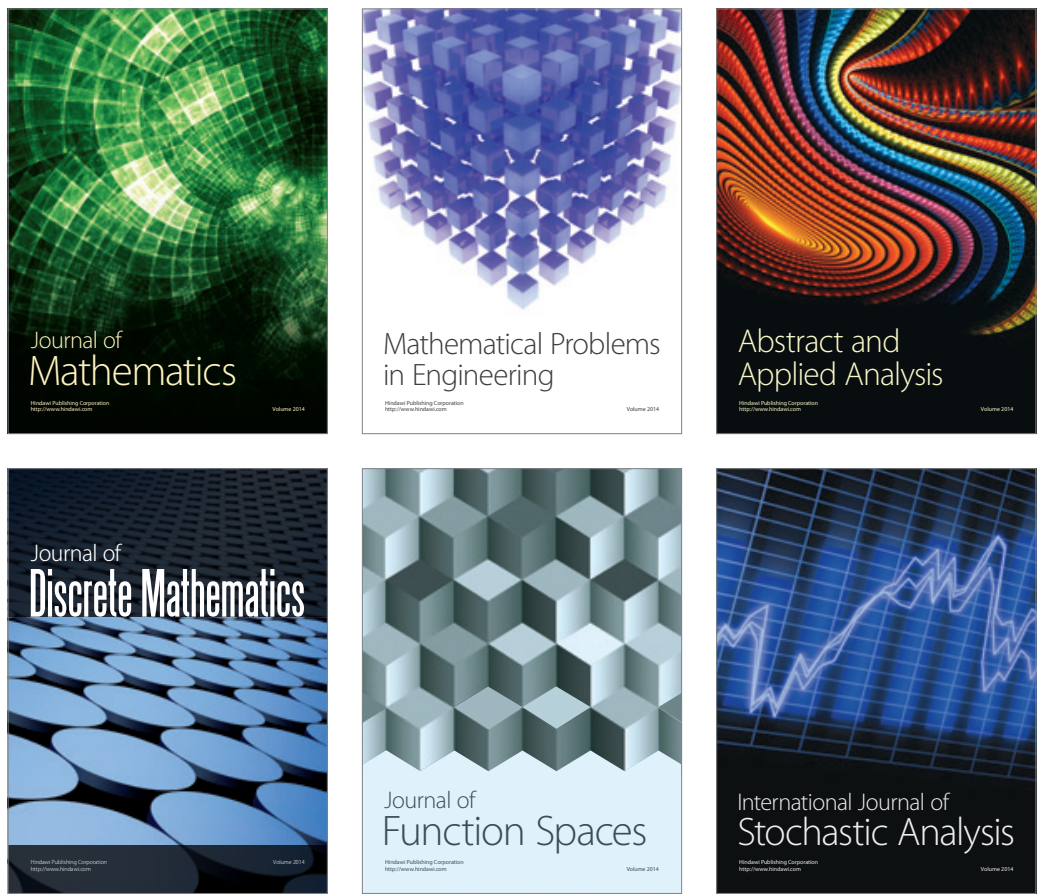

Journal of

Function Spaces

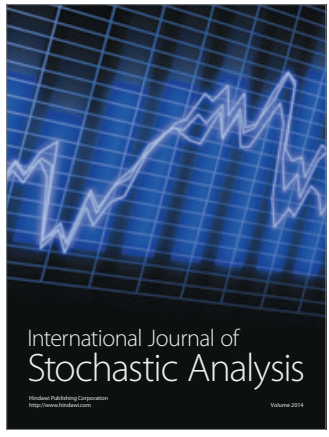

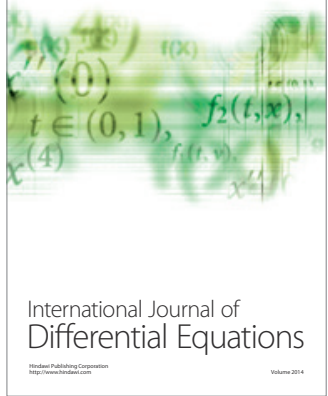
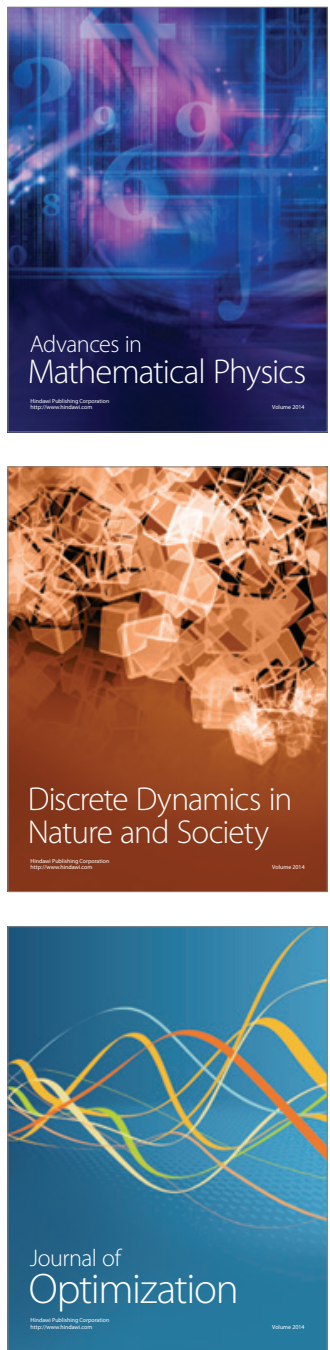